Ręka Gabriela, Machowiec Piotr, Maksymowicz Marcela, Piecewicz-Szczęsna Halina. Musicians' medicine - potential health problems among violinists and violists caused by playing the string instrument - the review of the literature. Journal of Education, Health and Sport. 2021;11(12):273-279. eISSN 2391-8306. DOI http://dx.doi.org/10.12775/JEHS.2021.11.12.020 https://apcz.umk.pl/JEHS/article/view/JEHS.2021.11.12.020 https://zenodo.org/record/5799671

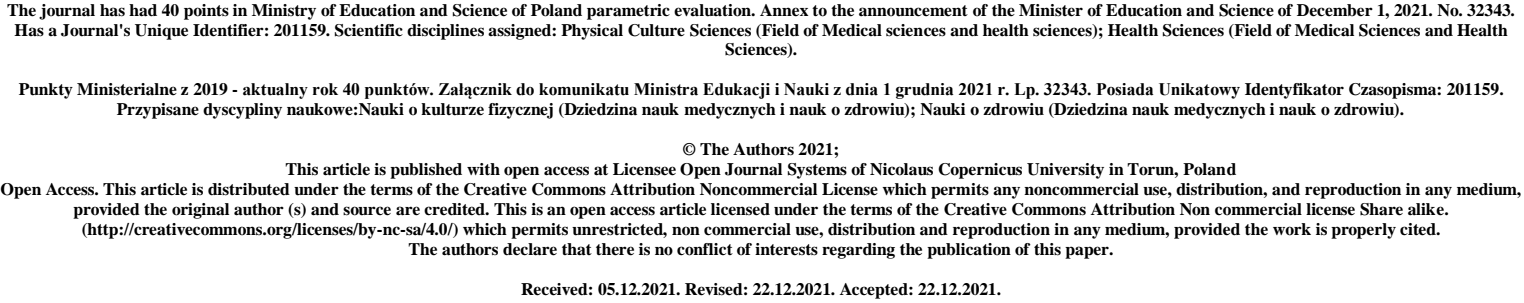

\title{
Musicians' medicine - potential health problems among violinists and violists caused by playing the string instrument - the review of the literature
}

\section{Gabriela Ręka, Piotr Machowiec, Marcela Maksymowicz, Halina Piecewicz-Szczęsna}

Gabriela Ręka ${ }^{1}$

gabrysia.reka@gmail.com, ORCID: 0000-0001-9728-5281

Piotr Machowiec ${ }^{1}$

piotr.machowiec1997@gmail.com, ORCID: 0000-0002-5418-0110

Marcela Maksymowicz ${ }^{1}$

marcela.maksymowicz@ gmail.com, ORCID: 0000-0003-2611-1609

Halina Piecewicz-Szczęsna²

halpiec@gmail.com, ORCID: 0000-0002-0573-7226

${ }^{1}$ Students' Scientific Association of Chair and Department of Epidemiology and Clinical Research Methodology, Medical University of Lublin, Radziwiłłowska 11, 20-080 Lublin

${ }^{2}$ Chair and Department of Epidemiology and Clinical Research Methodology, Medical University of Lublin, Radziwiłłowska 11, 20-080 Lublin 


\section{Abstract \\ Introduction and purpose}

Musicians' medicine has received increasing attention recently. It is known that listening to music or playing an instrument has beneficial effects on cognitive and neural functions. Playing the string instrument demands repetitive precise movements of fingers and arms in a non-ergonomic posture that might give rise to health problems.

The study aims to present the current state of knowledge regarding different potential health problems among violinists and violists. The article reviews the 24 newest scientific publications available on PubMed and Google Scholar.

\section{A brief description of the state of knowledge}

The literature review indicated several potential health consequences of excessive playing the violin or viola, as follows: Fiddler's neck and skin allergy, Garrod's pads, temporomandibular disorders, carpal tunnel syndrome, cubital tunnel syndrome, tennis elbow, compression of the right ulnar nerve in the ulnar (Guyon's) canal, rotator cuff tendonitis, tenosynovitis, bursitis, focal dystonia, thoracic outlet syndrome, bone asymmetry, pain in the neck, cheeks, fingers, wrist, forearm, shoulder, waist, and the back.

\section{Conclusions}

Musicians should be aware of potential health problems that occur during prolonged playing the violin or the viola. An important issue is maintaining the accurate proportions between the amount of time spent playing the instrument and resting. The first signs of neurological or musculoskeletal changes should prompt the musician to seek professional medical help to prevent the disorder's progression.

Key words: health; overuse injury; nerve entrapments; muscle pain; string instrument

\section{Introduction and purpose}

Musicians' medicine has received increasing attention recently. It is known that listening to music or playing an instrument has beneficial effects on cognitive and neural functions. It is noticed that musicians are characterized by training-related plasticity of the nervous system compared to non-musicians [1]. However, excessive, prolonged training and lack of breaks during playing the instrument might cause playing-related disorders. Such work-related medical problems are called occupational overuse syndrome. Playing the string instrument demands repetitive precise movements of fingers and arms in a non-ergonomic posture that might induce health problems [2]. The disturbances result not only from the time of playing the instrument and the effort put into producing the sound, but also from the awkward position the instrument is held and the nature of the left or right-hand movements that the violinist or violist must perform. Skin lesions, temporomandibular disorders, neck pain, musculoskeletal, and nerve disorders are enumerated in the literature $[3,4,5,6,7,8]$. Neuro-mechanical disorders are usually non-traumatic. However, they might lead to pain and prolonged or even permanent injury that impairs further practicing and playing [3]. 
The aim of the study is to present the current state of knowledge regarding different potential health problems connected with playing the instrument that might occur in violinists and violists. The article reviews 24 scientific publications available on the PubMed and Google Scholar platforms from 2012 to 2021.

\section{A brief description of the state of knowledge}

Fiddler's neck and skin allergy

Irritant contact dermatitis of the submandibular neck on the left side is called 'fiddler's neck'. Prolonged holding the violin or viola between the left shoulder and the neck causes repetitive localized mechanical pressure, friction, and shear stress. Fiddler's neck is a benign, but significant cutaneous irritation that can present as erythema, scarring, edema, and sometimes as pigmented lesion or lichenification $[4,9,10]$. It might be mistaken for a salivary gland malignancy or lymphedema [11]. Management of the fiddler's neck contains a topical steroid, neck padding by putting a cushion between the chin rest and neck, changing the instrument's materials and positioning, and shortening the amount of playing time. There is usually no need for surgical resection of the lesion [4,11].

Nickel, propolis, colophony (rosin), or exotic woods might cause allergic contact dermatitis of violinists and violists [4,10]. An allergic form of fiddler's neck appearing on the supraclavicular neck might be caused by nickel bracketing attaching the chin rest to the violin or viola. The rubber grip component of a violin bow was also described in the literature as a reason for skin allergy [4].

\section{Garrod's pads}

Garrod's pads are also described as violinist's pads or knuckle pads. They are calluses often seen on the dorsal proximal interphalangeal joints of the index or middle fingers [4]. They result from repeated extreme tension of the extensor tendons over the joints. Garrod's pads tend to be focal and affect the extensor and dorsal surfaces of the fingers and hands rather than the radial and ulnar parts. Some authors classify them as variants of pachydermodactyly [12].

Temporomandibular disorders

Being for hours in the position of clamping the violin or viola with the chin and the left shoulder produces a chin pressure on the chin rest that affects the temporomandibular joints and the cranio-cervico-mandibular complex. Abnormal musicians' postures during practicing and performance might cause muscular hyperactivity of the head and cervical muscles, with the possible occurrence of temporomandibular disorders [5,13]. Habar et al. enrolled 68 violinists from orchestras in Indonesia in the study. They completed the questionnaires and were examined afterward, which included the measurement of mouth opening and the palpation of head and neck muscles. Pain during palpation of the masseter muscle was felt by $35 \%$ of violinists $(25 \%$ in the right masseter muscle and $75 \%$ in the left masseter muscle). Palpation of the temporal muscle caused pain in $60 \%$ of subjects $(40 \%$ in the right temporal muscle and $60 \%$ in the left temporal muscle). Clicking was reported by $20 \%$ of subjects [5]. The prolonged training of a stringed instrument held between the chin and shoulder may subject the mandible to compressive forces. 
This unique positioning might be a reason for asymmetric micrognathia. Right-sided facial dominance with an underdeveloped left mandible was reported in cephalometric studies [14]. It is estimated that $62 \%$ of violinists and violinists suffer from submandibular lesions [15].

Nerve and tendon disorders

Playing a violin or viola demands repetitive, fast, and complicated movements of both hands and fingers [16]. Holding down and releasing the strings, rapid movements between the positions of the notes, up and down the neck of the instrument, and excessive internal rotation of the left arm and flexion of the left wrist involves a change in wrist and elbow angles. Such a position might induce carpal tunnel syndrome (a disorder of the median nerve) and flexor carpi ulnaris tendonitis. Prolonged flexion of the left elbow might contribute to ulnar neuropathy (cubital tunnel syndrome) or ulnar nerve entrapment at the elbow and wrist. Injury at the tendon sheaths, at the fingers, and at the muscles that move them might be caused by repetitive dynamic movements [3]. The right upper arm is elevated during bowing by $30-90^{\circ}$ for as long as a fourth of the playing time of a violinist. The prolonged state of abduction and flexion of the right shoulder can result in rotator cuff tendonitis. Myofascial tension on the pronator teres muscle, compression of the median nerve (resembling carpal tunnel syndrome), and evoke entrapment of the ulnar nerve might be induced by sharp full range pronation of the right forearm with an extension of the elbow on down-stroke. Compression of digital nerves from gripping the bow tightly also leads to carpal tunnel syndrome. Tremolo playing (bowing rapidly up and down in a state of isometric contraction of the muscles of the neck, shoulder-girdle complex, and the wrist flexors and extensors) might lead to an overuse injury of the extensor carpi radialis, flexor carpi ulnaris muscletendon units, and compression of the right ulnar nerve in the ulnar (Guyon's) canal. Less common radial nerve entrapment, also known as tennis elbow, can happen by overuse of the arm, forearm, and hand muscles when the arm is frequently bent and extended, which results in elbow pain. Tenosynovitis, bursitis, and wrist tendonitis (like De Quervain's syndrome) are other common health problems among violinists [3]. Vastamäki et al. assessed that violinists or violist suffered from more intensive hand pain and more frequent neck pain than other musicians in the orchestra. However, the disorders disturbed their daily tasks only a little [16]. Treatment is symptomatic or surgical depending on the intensity of the condition and available methods of management.

Focal dystonia

Focal hand dystonia is characterized by a sudden, involuntary loss of control and coordination of finger movements during instrumental playing. This task-specific movement disorder is correlated with forceful and extensive use of the digits and co-contraction of antagonist and agonist muscles. The maladaptive cortical reorganization altered sensory perception, and abnormalities in temporal and spatial discrimination are supposed to be responsible for the focal dystonia [17]. According to the systematic review concerning musculoskeletal disorders in professional violinists and violists made by Moraes and Antunes, focal dystonia was responsible for $5-10 \%$ of the musculoskeletal problems observed most often in musicians [15]. 
Task-specific motor training combined with neuromodulation, sensory re-education and sensory-motor returning, behavior treatment, constraint-induced therapy, slow-down exercise therapy and immobilization, proprioceptive training, and pharmacologic therapy are enumerated among methods of treatment [17].

Thoracic outlet syndrome

Thoracic outlet syndrome is a neurovascular condition involving the upper extremity, which occurs after chronic repetitive activity of the arm. It is caused by the pressure on the brachial plexus and subclavian and axillary vessels. Thoracic outlet syndrome presents with non-specific neuromuscular symptoms and includes pain, paresthesia, fatigue, weakness, or tingling of the affected arm [6,18]. In the study by Adam et al. abnormal ultrasound scan with vascular compression was detected in $69 \%$ of musicians ( $74 \%$ of the violin or viola players), in contrast to $15 \%$ of the control group $(p=0.03)$. Positive Elevated Arm Stress Test (EAST) and Upper Limb Tension Test (ULTT) in the musician group were $44 \%$ and in the control group 3\% $(p=0.03)$ [18]. Surgical treatment including first rib resection, scalenectomy, and brachial plexus neurolysis might be implemented in serious cases of the syndrome [6].

\section{Other musculoskeletal disorders}

Although most violinists and violists practice alone standing up, playing in the orchestra or the chamber ensembles requires sitting on the chair in front of the note stand that might be at the wrong angle or wrong height. Repetitive and inappropriate postures by carrying the instrument and holding the bow for a long time cause the disorders [17]. Violinists typically experience pain in some areas of their body when and after playing the instrument. The pain was felt mainly in the neck (29.55\%), chin $(28.41 \%)$, and shoulders (27.27\%). Violinists also experienced pain in the back, upper arms, forearms, fingers, waist, cheeks, and ears [5]. Passages requiring rapid changes over the four strings of the violin and viola may strain the right rotator cuff, deltoid, and pectoralis muscles [3].

In the study by Kok et al. complaints of the neck-shoulder region were significantly associated with the muscle activity of some superficial neck and shoulder muscles and were not significantly associated with the violin fixation force [19]. Playing-related neck pain in violinists or violists is linked with changes in neuromuscular control of cervical muscles and altered behavior of the superficial neck flexors. They are consistent with pain in the neck, despite the specific use of the superficial and deep neck flexor muscles [20]. The study suggested that smaller hand size and the use of a shoulder rest changes muscle activity are correlated to increased incidence of playing-related musculoskeletal disorders [21]. Topdemir et al. in the randomized controlled trials of 117 violinists showed beneficial effects of Kinesio taping applied for one week. It provides minor improvements in playing-related pain and post-performance pain intensity with the slightly retained grip strength of the left hand [22].

Cygańska et al. evaluated body parameters for trunk symmetry in 101 child violinists and compared them with the control group of 52 children. Some parameters of the curvature of the vertebral column in the frontal plane were altered due to the position maintained while playing the violin. A positive correlation between the height of the body and the difference in distance of the lower scapulae corners from the vertebral column was noted. 
Statistically significant differences for the difference in depth of the lower corners of scapulae and upper posterior iliac spine were found in the study group. However, greater asymmetries were noted in the control group [23]. In another work of the same authors, the body posture of 49 child violinists and a control group of 52 children not playing any instrument was evaluated. Significant differences in the thoracolumbar region angle were noted in the study group compared to the non-musical children. Another parameter that was significantly higher among the violinists' group characterized the location of the kyphosis peak calculated from the spinous process of the seventh cervical vertebra [24].

The literature mentions several methods how to alleviate consequences of excessive playing the instrument: warming-up prior to playing, reduction of practice time, rest periods during training sessions, modifications of improper techniques, adequate hydration and eating habits, ergonomic postures at home and at work, frequent stretching exercises and use of chin, shoulder rests, and appropriate furniture. The provision of adequate information to violinists and violists is helpful in increasing awareness regarding postural problems and disease prevention [15].

\section{Conclusions}

Musicians who perform bowed string instruments should be aware of potential health problems that occur during prolonged playing the violin or the viola. An important issue is maintaining the accurate proportions between the amount of time spent playing the instrument and relaxing. The first signs of neurological or musculoskeletal changes should prompt the musician to seek professional medical help to prevent the disorder's progression, prolonged pain, or even permanent injury that might impair further practicing and playing.

\section{References}

1. White-Schwoch T, Carr KW, Anderson S, Strait DL, Kraus N. Older adults benefit from music training early in life: biological evidence for long-term training-driven plasticity. J. Neurosci. 2013;33(45):17667-17674. doi: https://doi.org/10.1523/JNEUROSCI.2560-13.2013.

2. Lee HS, Park HY, Yoon JO, Kim JS, Chun JM, Aminata IW, Cho WJ, Jeon IH. Musicians' medicine: musculoskeletal problems in string players. Clin Orthop Surg. 2013;5(3):155-60. doi: 10.4055/cios.2013.5.3.155.

3. Mizrahi J. Neuro-mechanical aspects of playing-related mobility disorders in orchestra violinists and upper strings players: a review. Eur J Transl Myol 2020;30 (3):9095. doi: 10.4081/ejtm.2020.9095.

4. Sheehan, M.P. Avocational contact dermatitis - pearls for recognition and management. Curr Treat Options Allergy. 2015;2:322-332. https://doi.org/10.1007/s40521-015-0065-x.

5. Ike Damayanti Habar, Andi Adytha M.I.R, Mohammad Dharma Utama, Bahruddin Thalib, Acing Habibie Mude, Muhammad Ikbal, Eri Hendra Jubhari. The prevalence of temporomandibular joint disorders in young violin players in two orchestras in Indonesia. Sys Rev Pharm 2020;11(9):3134.

6. Demaree CJ, Wang K, Lin PH. Thoracic outlet syndrome affecting high-performance musicians playing bowed string instruments. Vascular. 2017;25(3):329-332. doi: $10.1177 / 1708538116671064$. 
7. Park KN, Jung DY, Kim SH. Trapezius and serratus anterior muscle strength in violinists with unilateral neck pain. J Back Musculoskelet Rehabil. 2020;33(4):631-636. doi: 10.3233/BMR181147.

8. Rensing N, Schemmann H, Zalpour C. Musculoskeletal demands in violin and viola playing: a literature review. Med Probl Perform Art. 2018;33(4):265-274. doi: 10.21091/mppa.2018.4040.

9. Geduk, G. Contact dermatitis: Fiddler's neck. $\mathrm{Br}$ Dent J. 2016;220:280. https://doi.org/10.1038/sj.bdj.2016.207.

10. Crépy MN. Skin diseases in musicians. Eur J Dermatol. 2015;25(5):375-83. doi: 10.1684/ejd.2015.2559.

11. Myint CW, Rutt AL, Sataloff RT. Fiddler's neck: A review. Ear Nose Throat J. 2017;96(2):76-79. doi: 10.1177/014556131709600210.

12. Liew ALF, Ting Y. Pachydermodactyly: A case report of a little-known and benign form of digital fibromatosis. Am J Case Rep. 2020;21:e923344. doi: 10.12659/AJCR.923344.

13. Clemente M, Coimbra D, Silva, A, Aguiar Branco C, Pinho JC. Application of infrared thermal imaging in a violinist with temporomandibular disorder. Med Probl Perform Art. 2015;30(4):251-254.

14. Boustany AN, Manstein SM, Lin SJ. Special considerations for chin augmentation in the professional violinist. J Craniofac Surg. 2021;32(8):e727-e728. doi: 10.1097/SCS.0000000000007706.

15. Moraes GF, Antunes AP. Musculoskeletal disorders in professional violinists and violists. Systematic review. Acta Ortop Bras. 2012;20(1):43-7. doi: 10.1590/S1413-78522012000100009.

16. Vastamäki M, Vastamäki H, Ristolainen L, Laimi K, Saltychev M. Violists and violinists report more intense hand pain on NRS than other orchestra musicians. Med Probl Perform Art. 2020;35(3):162-166. doi: 10.21091/mppa.2020.3024.

17. Chiaramonte R, Vecchio M. Rehabilitation of focal hand dystonia in musicians: a systematic review of the studies. Rev Neurol. 2021;72(8):269-282. doi: 10.33588/rn.7208.2020421.

18. Adam G, Wang K, Demaree CJ, Jiang JS, Cheung M, Bechara CF, Lin PH. A Prospective evaluation of duplex ultrasound for thoracic outlet syndrome in high-performance musicians playing bowed string instruments. Diagnostics (Basel). 2018;8(1):11. doi: 10.3390/diagnostics8010011.

19. Kok LM, Schrijvers J, Fiocco M, van Royen B, Harlaar J. Differences in violin fixation force and muscle activity among violinists with and without complaints of the neck shoulder region. $\mathrm{J}$ Electromyogr Kinesiol. 2018;43:217-225. doi: 10.1016/j.jelekin.2018.11.002.

20. Steinmetz A, Claus A, Hodges PW, Jull GA. Neck muscle function in violinists/violists with and without neck pain. Clin Rheumatol. 2016;35(4):1045-51. doi: 10.1007/s10067-015-3000-4.

21. Chi JY, Halaki M, Ackermann BJ. Ergonomics in violin and piano playing: A systematic review. Appl Ergon. 2020;88:103143. doi: 10.1016/j.apergo.2020.103143.

22. Topdemir E, Birinci T, Taşkıran H, Mutlu EK. The effectiveness of Kinesio taping on playing-related pain, function and muscle strength in violin players: A randomized controlled clinical trial. Phys Ther Sport. 2021;52:121-131. doi: 10.1016/j.ptsp.2021.08.010.

23. Cygańska A, Truszczyńska-Baszak A, Drzał-Grabiec J, Tarnowski A. Assessment of body parameters' symmetry in child violinists. J Back Musculoskelet Rehabil. 2017;30(5):1081-1086. doi: 10.3233/BMR-169700.

24. Cygańska A, Truszczyńska-Baszak A, Drzał-Grabiec J, Tarnowski A. Analysis of anteroposterior spinal curvatures in child violinists from music schools. Med Probl Perform Art. 2017;32(3):176-179. doi: 10.21091/mppa.2017.3029. 